\section{The 'Burden' of the Member Magazines}

\section{Christian Remenyi ${ }^{\star}$}

${ }^{*}$ Correspondence: Dr. C. Remenyi, E-mail: c.remenyi@gdch.de Nachrichten aus der Chemie, German Chemical Society (GDCh), D-60486 Frankfurt am Main, Germany

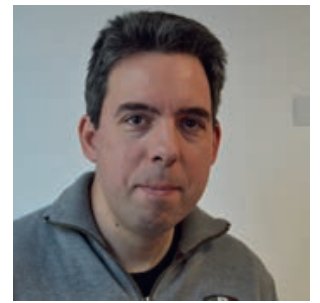

Christian Remenyi, Editor in-chief Nachrichten aus der Chemie

A few years ago, Chemistry Europe (then called ChemPubSocEurope), the European publishing organization of 16 chemical societies including SCS and GDCh, invited the editors of its member journals to a meeting. This was a wonderful opportunity to get to know the many different - and in some respects very similar - member journals. And for me, it also was the first opportunity to talk about our two journals with Gillian Harvey, the technical editor in charge of the production of CHIMIA.

It is the typical déformation professionnelle of the magazine editor: just reading for fun is not possible. You are constantly comparing, looking for things that others have solved better and smiling when you discover tiny mistakes (which you would never make yourself, of course...).

\section{What member magazines have to do}

The challenges facing us member magazines of the European chemical societies are similar. There are many tasks to be fulfilled at the same time: We have to be the newsletter of the respective society, keep an eye on the balance between members and interests from industry and academia, and offer lots of services to our readers - they want to know about meetings, birthdays, and book reviews. And the science must always be correct, too. Although we are not purely professional journals, there is no tolerance zone. But one of the most important tasks of our

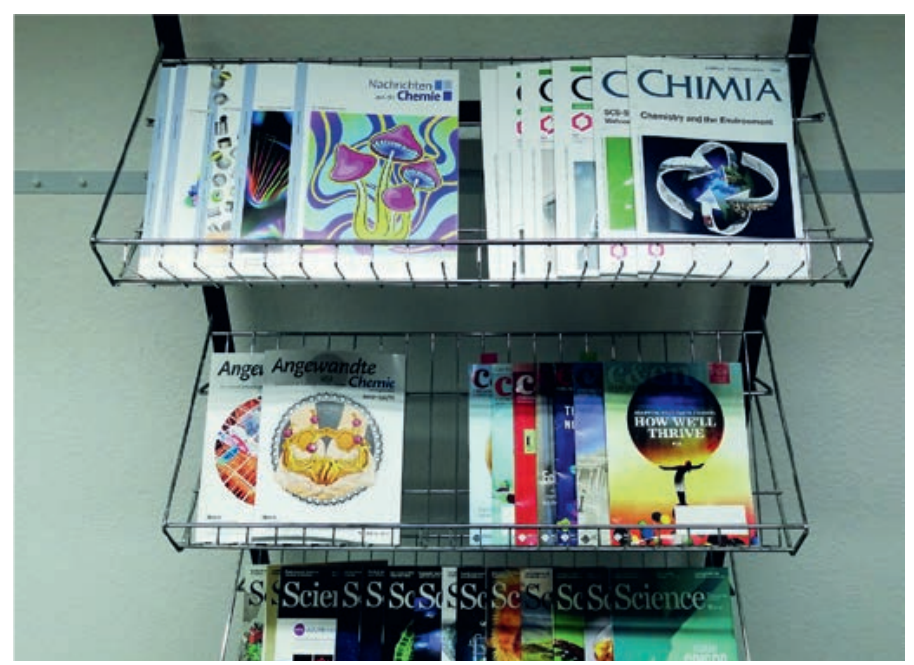

Shoulder to shoulder in the magazine rack: Nachrichten aus der Chemie and CHIMIA (and some other not so important journals...) journals is to give readers the feeling that they are part of a large community of like-minded people, the chemistry community, beyond the boundaries of their special disciplines.

CHIMIA and Nachrichten aus der Chemie are about the same age (well, Nachrichten aus der Chemie is the younger sister of CHIMIA, which is six years older...). But while CHIMIA still very much emphasizes its character as a professional chemistry journal, Nachrichten defines itself more as magazine style and has become steadily more colorful over the years (some would even say more like a tabloid).

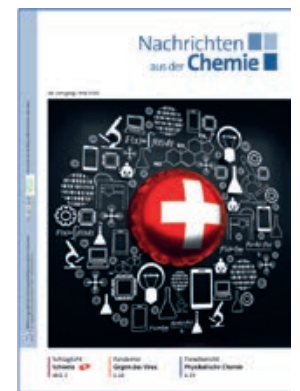

Focus issue 'Switzerland' of Nachrichten aus der Chemie 5/2020[1]

\section{International Impact}

For me it is impressive how CHIMIA, despite not having a major publisher in the background, is among the frontrunners in modern publishing developments - be it electronic publishing or open access. The journal thus directs its focus far beyond the limited readership in Switzerland and addresses a worldwide audience.

For this, CHIMIA is a great role model for us in terms of internationalization. Whereas one of the unique selling points of Nachrichten aus der Chemie is its German-language content, which makes sense with a target group of more than 30,000 German-speaking GDCh members, CHIMIA is the only member journal of a European chemical society to rely fully on English as the international language of science. (A magazine in the national language would also be associated with difficulties in multilingual Switzerland; the Belgian colleagues solve the problem by having their own Flemish-language and Frenchlanguage chemistry societies...).

But it is clear that if you want to make an international impact, you have to do it in the lingua franca of chemistry, even if it may be comfortable in the national corner. CHIMIA succeeds exceptionally well in this art - preserving the national identity of its "own" chemical society while addressing the global chemistry community.

I wish CHIMIA continuing success for the next 75 years and its readers much pleasure with the journal!

[1] Schlaglichtheft 'Schweiz', Nachr. Chem. 2020, 68 (5), 1-100, https:// onlinelibrary.wiley.com/doi/toc/10.1002/(ISSN)1868-0054.schweiz-2020, with an article especially for CHIMIA, https://onlinelibrary.wiley.com/ doi/10.1002/nadc.20204095921. 